\title{
QUALIDADE DA DEMOCRACIA NA AMÉRICA LATINA: ANÁLISE DA CONFIANÇA DOS CIDADÃOS NA MÍDIA E NAS INSTITUIÇÕES
}

\author{
QUALITY OF DEMOCRACY IN LATIN AMERICA: ANALYSIS OF THE \\ CONFIDENCE OF CITIZENS IN THE MEDIA AND INSTITUTIONS
}

\author{
Bruno da Silva Conceição ${ }^{1}$, Camila de $\operatorname{Vasconcelos}^{2}$ e Rodolfo Silva Marques ${ }^{3}$
}

\section{RESUMO}

As democracias latino-americanas têm apresentado fortes indícios de desconfiança da população com relação as instituições políticas. Isso propicia temores de retrocessos autoritários em razão da incapacidade das instituições se consolidarem na região. Nesse debate, as mídias possuem grande relevância sobre a formação da opinião pública e a possível instabilidade democrática, pelo poder de influência que os sistemas de comunicação e o conteúdo veiculado nos meios têm na população. Dessa forma, o presente paper questiona de que forma estão relacionadas as predisposições de confiança da população na mídia e nas instituições políticas na América Latina. A desconfiança na mídia é similar ao das outras instituições políticas? A hipótese de pesquisa apresentada é de que a confiança dos cidadãos na mídia está relacionada de forma inversamente proporcional à confiança destes em relação às instituições políticas. Para viabilizar a discussão dessa hipótese, utilizam-se os dados de percepção de qualidade democrática levantados pelo Latinobarômetro, ano de 2015, comparando a associação dessas variáveis entre os países da América Latina. Os resultados colhidos indicam, contrariamente à nossa hipótese de pesquisa, que a desconfiança da população da América Latina tem o mesmo grau de direcionamento quando se consideram o funcionamento da mídia e das próprias instituições políticas. Isso indica que as instituições que sustentam a democracia na região estão sem respaldo popular.

Palavras-chave: Mídia; Democracia; Instituições; América Latina.

\section{ABSTRACT}

Latin American democracies have shown strong signs of public distrust of political institutions. This gives rise to fears of authoritarian setbacks because of the inability of institutions to consolidate themselves in the region. In this debate, the media has great relevance on the formation of public opinion and the possible democratic instability, for the power of influence that the communication systems and the content conveyed in the media have within the population. Thus, this paper questions how the population's predispositions of trust in the media and political institutions in Latin America are related. Is the mistrust in media similar to others in political institutions? The research hypothesis is that public trust in the media is inversely related to their confidence in political institutions. In order to facilitate the discussion of this hypothesis, we use the data of democratic quality perception raised by the Latinobarometro, from 2015, comparing the association of these variables among Latin American countries. The results obtained indicate, contrary to our research hypothesis, that the distrust of the population of Latin America has the same degree of direction when considering the functioning of the media and the political institutions themselves. This indicates that the institutions that sustain democracy in the region are without popular support.

Keywords: Media; Democracy; Institutions; Latin America.

\footnotetext{
${ }^{1}$ Doutor em Ciência Política (UFRGS). E-mail: brunopolitica@gmail.com

${ }^{2}$ Doutora em Ciência Política (UFRGS). Professora no IFG-Luziânia. E-mail: camilavas89@gmail.com

${ }^{3}$ Doutor em Ciência Política (UFRGS). Professor na UNAMA. E-mail: rodolfo.smarques@gmail.com
} 


\section{INTRODUÇ̃̃̃O}

A falta de confiança nas instituições políticas tem sido um fator relevante para avaliação negativa das democracias na América Latina neste novo século. Entre as principais reclamações dos cidadãos, com relação à baixa efetividade dessas instituições, estão: o alto índice de violência urbana nas grandes metrópoles; o déficit em políticas públicas para a saúde e para educação; e a corrupção "generalizada" nas instâncias administrativas de governo (MOISÉS, 2010). Tanto a ausência de respostas da classe política aos problemas da população, quanto o histórico de instabilidade institucional da região reforçam para que as democracias latino-americanas sejam apontadas como instáveis. Tais atitudes de desconfiança com as instituições políticas podem vir a desestabilizar os sistemas democráticos, uma vez que para os governos é fundamental o apoio dos cidadãos para legitimar suas ações políticas (MOISÉS e MENEGUELLO, 2013; IAZZETTA, 2013).

Por outro lado, a mídia possui função fundamental na construção da percepção que o povo tem de seus governantes, pois apresenta informações e notícias, todos os dias, sobre vários níveis da política, nas diferentes escalas geográficas. Ou seja, interfere, para o bem ou para o mal, na predisposição da população com as instituições políticas. Dentro desse debate existe uma corrente no campo da comunicação que identifica a mídia como uma instituição exercendo poder por meio dos conteúdos veiculados que influencia na confiança, ou desconfiança, da população nas demais instituições (STROMBACK; VAN AELST, 2013). A mídia, nesse contexto, teria um viés de uma instituição semi-independente que perpassa instituições políticas e sociais (HJARVARD, 2001).

Nesse contexto, a agenda de pesquisa sobre a qualidade das democracias busca encontrar os fatores que impedem a completa efetivação da democracia. Essa temática perpassa o debate teórico de quais seriam essas características essenciais, ou necessárias, dentro do conceito de democracia, mas também assume que este conceito pode ser desconstruído com o tempo. A qualidade da democracia seria medida pela confiança da população nas suas instituições que sinalizariam se estão satisfeitas com este regime (TILLY, 2007; IAZZETTA, 2013; DIAMOND e MORLINO, 2004; SCHMITTER, 2004; MORLINO, 2010; BAQUERO, 2012; LAUTH, 2013; MOISÉS e MENEGUELLO, 2013).

Entretanto, é importante entender a usabilidade dos indicadores disponíveis para a mensuração da qualidade das democracias. Alfredo Gugliano (2013) levanta questionamentos sobre classificações utilizadas por institutos, como a Freedom House ${ }^{4}$, considerando que alguns critérios institucionais e eleitorais são insuficientes para dar conta da qualidade das democracias nos países latino-americanos. Alinhado a isso, existem oposições também à metodologia utilizadas por esses institutos que colocam sempre os países do Norte global como mais democráticos (GUGLIANO, 2013). Munck e Mantilla (2013) amplificam a discussão, ao apontarem diversas perspectivas metodológicas mais substantivas,

\footnotetext{
${ }^{4}$ É uma organização sem fins lucrativos, com sede em Washington D.C. nos Estados Unidos da América, que promove e analisa a qualidade da democracia de vários países no mundo.
} 
avaliando como predominante, até o momento, a ideia de que o sistema democrático e a qualidade da democracia estão ligados aos aspectos procedimentais, estruturais e os de resultado.

Explora-se aqui a inserção de variáveis culturais para esse debate, na medida em que se considera como parâmetro as percepções de confiança da população como fatores relevantes para avaliações da qualidade democrática. Dessa forma, é possível inferir a qualidade das democracias da região latino-americana frente à percepção dos cidadãos com as instituições políticas e a mídia. Objetiva-se identificar se a percepção de confiança das pessoas nos meios de comunicação é semelhante ou discordante da visão que a população tem em relação às instituições políticas. A hipótese de pesquisa é de que a confiança dos cidadãos na mídia está relacionada de forma inversamente proporcional à confiança deles em relação às instituições políticas. Para viabilizar o teste dessa hipótese, utilizam-se dados levantados pelo questionário do Latinobarômetro, no ano de 2015, entre os países da América Latina 5 .

Na América Latina, a década de 1970 foi o período crucial de saída de regimes autoritários para uma democracia eleitoral, ancorada nos partidos políticos competindo pelo poder em eleições cada vez mais frequentes. Esse fenômeno de transição de uma quantidade significativa de países com regimes autoritários para tornarem-se regimes democráticos é denominado por Samuel Huntington (1994) de 'terceira onda de democratização'. 'Uma onda normalmente envolve também liberalização ou democratização parcial nos sistemas políticos que não se tornam completamente democráticos” (HUNTINGTON, 1994, p.23).

Domenico Hur e Fernando Lacerda júnior (2017) analisam que os processos de transição democrática foram feitos de maneira diferenciada, em cada país, em virtude da intensidade de repressão que os regimes ditatoriais tiveram em cada país. "As ditaduras civis-militares na América Latina e no Brasil surgiram para garantir a subordinação dos países latino-americanos ao sistema imperialista e para reprimir toda mobilização popular que almejasse reversão dos padrões de superexploração" (HUR e LACERDA JR, 2017, p.29). A violência da repressão, notadamente na Argentina, no Uruguai, no Chile, na Nicarágua, em El Salvador e no Brasil, resultou em um expressivo número de desaparecidos, de torturados e de mortos.

Os impactos da repressão as liberdades individuais foram vistas também na liberdade de imprensa. Por um lado, os meios de comunicação tiveram que conviver, durante os períodos de chumbo, com censura de notícias que implicassem constrangimentos aos militares no poder. De outro lado, algumas empresas jornalísticas prosperaram nesse período fazendo "vista grossa" aos casos de corrupção e violência dos mandatários de poder (MARQUES, 2018). Esses recortes históricos singulares podem indicar diferenças na percepção que os cidadãos vão ter tanto das instituições políticas quanto dos meios de comunicação. O enviesamento de setores da mídia com a classe política pode ser resquício das proibições das matérias pelo Estado autoritário e pelo direcionamento editorial "chapa branca" dos veículos de comunicação nos anos de repressão.

\footnotetext{
${ }^{5}$ São os países analisados, em ordem alfabética: Argentina, Bolívia, Brasil, Chile, Colômbia, Costa Rica, Equador, El Salvador, Guatemala, Honduras, México, Nicarágua, Panamá, Paraguai, Peru, República Dominicana, Uruguai e Venezuela.
} 
Portanto, passadas décadas de consolidação democrática que ocorreram por meio da normatização de eleições regulares, teríamos o momento adequado de avaliar se a mudança de regimes políticos foi concluída nos países latino-americanos. Guillermo O’Donnell (2011) já nos apontava que a percepção da sociedade acerca dos países da América Latina é de desconfiança nas suas respectivas instituições políticas. O referido autor analisou dados do Latinobarômetro de 2003, onde verificou que a média de respostas com "nenhuma confiança" nos partidos chegou a 45\%; nos Congressos chegou a 36\%; nos Judiciários chegou a 26\%; e nos Tribunais Eleitorais chegou a 21\%. Para O’Donnell, o legado autoritário ainda perpassa esses países que convivem com aumentos consideráveis de democratização, mas que são avanços morosos em meio a Estados nacionais ineficientes, patrimonialistas e que cujos líderes, por vezes, governam sem freios institucionais. Identificar alguma melhora recente nos prognósticos de democratização, após mais ciclos eleitorais, é um dos objetivos desta pesquisa.

A agenda sobre a qualidade das democracias é relativamente nova dentro dos estudos de cultura política no século XXI. Havia o predomínio de estudos sobre a democracia numa visão minimalista. As pesquisas eram pautadas apenas nas eleições e deixavam de fora aspectos substantivos da vida dos países como a satisfação com os governos, a liberdade de imprensa, o respeito aos direitos humanos, a desigualdade econômica (DAHL, 1971; PRZEWORSKI et al. 1996). Entretanto, avaliar a qualidade da democracia significaria ultrapassar o viés procedimental para mensurar os resultados efetivos das instituições políticas na vida do cidadão. Dessa forma, não basta a existência de eleições regulares se a cidadania, a participação, a liberdade, os direitos humanos ou o bem-estar social não são garantidos e protegidos pelo Estado.

Neste quesito, alguns rankings surgiram a fim de listar em uma escala democrática os diferentes países. A proposta do instituto Freedom House constitui um dos mais importantes rankings democráticos e aborda dimensões econômicas e culturais. Contudo, há um permanente questionamento sobre seu viés político interferindo as análises dessas dimensões, uma vez que podem ser verificadas constantes paradigmas neoliberais sobre seus reports ao longo de diversos períodos (GIANNONE, 2010). Tal problemática têm levado os pesquisadores a empreenderem uma metodologia mais abrangente dos conceitos de democracia relacionando vários eixos, desde a esfera procedimental das eleições, até a esfera da participação dos cidadãos (AMORIM; DIAS, 2012).

Nesse sentido, Morlino (2007) debate que o conceito de qualidade da democracia deveria levar em conta duas exigências: 1) a democracia plena exista ou seja algo realizável, e 2) as normas éticas ou idealistas esperadas em uma democracia possam ser encontradas por via de uma análise empírica. De fato, uma qualidade democrática só pode ser auferida se o país cumpre os requisitos mínimos de uma democracia representativa, quais sejam: sufrágio universal; eleições livres e regulares; competição entre partidos; variedade de informações (MORLINO, 2007).

Tal avaliação sobre a qualidade da democracia significaria ainda mensurar a eficácia de políticas públicas dos governos oriundos de mudança de regime político, por meio de análise sobre o 
crescimento de direitos civis, na ampliação da cidadania, no aumento da participação popular nos assuntos públicos, na avaliação da liberdade de expressão, no comprometimento com leis que preservem os direitos humanos, etc. Desse modo, o Estado deveria ser avaliado em uma perspectiva que ultrapassasse o aspecto procedimental de eleições e funcionamento de instituições. O essencial seria avaliar a satisfação dos cidadãos com as políticas públicas, executadas pelos governos na região, para medir a qualidade dessas democracias (ÁVILA, 2017).

Segundo uma visão etimológica do termo “qualidade”, Morlino (2007) salienta que um produto para ter qualidade atestada precisa ir além de ser confiável e com conteúdo inteligível. O produto precisa criar satisfação no consumidor. Morlino (2007) define, assim, três hipóteses possíveis de formatos de qualidade democrática que satisfaçam os consumidores: 1) quando a população está plenamente satisfeita com os resultados propiciados pelas instituições políticas; 2) quando a população está satisfeita com o conteúdo das instituições democráticas, ou seja, consegue comparar melhoras visíveis em relação a igualdade e liberdade caso estivesse em um regime autoritário; e 3) quando a população está satisfeita com os procedimentos de seleção dos governantes e o respeito as normas vigentes. Portanto, a qualidade democrática pode ser alicerçada em cada um desses eixos (resultados, conteúdo e regras) sem serem mutuamente excludentes. O esperado seria que um regime democrático alcançasse uma qualidade elevada nessas três dimensões (MORLINO, 2007).

A perspectiva culturalista ${ }^{6}$ da Ciência Política considera como variável relevante para o desenvolvimento das democracias as atitudes e os comportamentos políticos dos cidadãos, contribuindo significativamente para a compreensão da qualidade das democracias. Os autores Almond e Verba (1965) defenderam que variáveis político-culturais são capazes de explicar as estruturas e os processos políticos. Assim, por meio da opinião de confiança política dos cidadãos, é possível compreender aspectos da cultura política de um país. Os autores argumentavam que a congruência entre a cultura política e as estruturas dos sistemas políticos podem ser cruciais para a manutenção dos regimes democráticos (ALMOND e VERBA, 1965). Para Inglehart e Welzel (2009), a modernização contribuiu para que as pessoas busquem a emancipação diante da autoridade. Os valores de autoexpressão também entram nessa discussão como uma forma de as pessoas se posicionarem diante dos temas recorrentes. Esses valores espalham-se para várias dimensões da vida como papéis de gênero, consumo e participação política (INGLEHART; WELZEL, 2009).

As predisposições dos cidadãos têm sido exploradas como variáveis significativas no processo de democratização em seus respectivos países. A relação atitudes-comportamentos pode ser

\footnotetext{
${ }^{6}$ Para esta abordagem, um certo nicho de valores culturais (por exemplo cultura cívica, confiança e capital social), é condição para a mudança política no que concerne a disjuntiva democracia/ não democracia. A manutenção da democracia estaria alicerçada nos valores culturais compartilhados pelos cidadãos, sob a forma de padrões atitudinais. Cultura política, para Almond e Verba (1965), é, pois, o modelo de atitudes e orientações diante da política entre os membros de um sistema político. Eles utilizam "cultura política de uma nação" ao invés de "cultura política nacional”, focando a questão nas pessoas e nos seus valores. Eles indicam duas explicações para o uso do termo cultura política: uma refere-se à especificidade de trabalhar com a esfera política; e outra está ligada ao uso do arcabouço teórico da antropologia, sociologia e psicologia.
} 
verificada pelas primeiras predizerem as segundas, se houver uma mensuração adequada (KRAUS, 1995). Neste caso há um grande esforço entre os pesquisadores de Cultura Política em realizar pesquisas que mensurem as atitudes políticas, por meio de surveys, principalmente, porque se espera que tais atitudes revelem comportamentos que possam impactar sobre as instituições políticas.

Para José Álvaro Moisés (2010), são necessários o apoio e o reconhecimento da população para que a democracia se consolide. Assim, se torna fundamental que os cidadãos compreendam e entendam a importância de estarem em um regime democrático e apoiá-lo como sistema político para que esse se aperfeiçoe. O significado que os cidadãos possuem sobre as instituições políticas pode ser reiterada a partir da avaliação racional do desempenho delas ao longo de sua vida adulta. $\mathrm{O}$ apoio dos cidadãos, portanto, provém da experiência que esses tiveram com o funcionamento das instituições e essas, como mecanismos de mediação política, devem ser utilizadas para agrupar os interesses da sociedade perante o Estado.

Na perspectiva de Robert Dahl (1971), a mídia possui papel indispensável, pois permite uma real ampliação de caminhos para a contestação dos governos pela sociedade. Neste processo participativo, tanto em contextos eleitorais quanto em momentos de insatisfação com mandatos representativos, acontece uma consolidação das instituições democráticas. Se os veículos de comunicação, em especial os jornais e a teelevisão, podem tender a distorcer a informação com alguma frequência, é importante destacar que os governos têm de ter maturidade para enfrentar críticas dentro do debate democrático. De outro lado, a mídia também precisa se monitorar para não virar, necessariamente, uma mídia "governista”. Para Dahl (1971), o maior número de informações disponíveis ao cidadão tende a incentivar o senso crítico e ampliar a contestação em relação a ações governamentais que possam trazer algum tipo de prejuízo.

Nesse sentido, é necessário reforçar a compreensão a respeito das interações da mídia com a democracia. Um dos conceitos importantes em voga é o de midiatização. De acordo com Lunt e Livinsgtone (2016), a tecnologia agiliza o acesso à informação e à sua difusão, tornando intensos os processos interativos na sociedade. No campo político, a midiatização se converte em um importante agente de mudanças culturais e sociais, gerando um processo no qual instituições políticos e sociais têm de se adaptar na medida em que a sociedade demanda por informação. Conforme Hjarvard (2012), a midiatização possibilita que a mídia seja vista por uma perspectiva institucional na medida em que consegue redistribuir o poder das instituições na sociedade. "Isso significa que se aplica um conjunto de conceitos sociológicos, o que torna possível especificar os elementos que compõem a lógica da mídia e analisar melhor a relação entre os meios de comunicação e outras esferas sociais (instituições)" (HJARVARD, 2012, p.60). Da mesma forma que a mídia possui uma autonomia institucional, há um intercâmbio dela com as demais instituições. Nessa perspectiva, a midiatização na política não seria a 
usurpação do poder das instituições políticas pela mídia, mas sim, a dependência destas instituições para com a mídia que performa um papel institucional próprio.

Por isso que analisar a confiança da população na mídia é crucial para esta pesquisa. Sua interferência tem sido cada vez mais constante na vida social e na compreensão que a população tem das questões e das instituições políticas, pois os veículos de comunicação controlam a difusão, o formato e os signos das mensagens políticas que são transmitidas. Isso pode possibilitar, conforme a hipótese dessa pesquisa, que a mídia possua uma confiança diferenciada das demais instituições tradicionais da política. A mediação da informação que ela controla produz que os sentidos que a população possa lhe atribuir sejam, talvez, menos críticos do que os das instituições políticas. O fenômeno da midiatização, portanto, interfere na visão de qualidade da democracia que as populações da América Latina vivenciam.

\section{METODOLOGIA}

Com relação as questões metodológicas, as pesquisas têm focado apenas aspectos mais substantivos do que normativos sobre os regimes políticos. Os aspectos procedimentais são relegados para o segundo plano, apesar de serem vistos como imprescindíveis, em detrimento de aspectos mais substantivos de efetividade democrática. Essa separação entre procedimentos institucionais e satisfação popular é uma dissociação prejudicial ao entendimento da qualidade da democracia, pois compromete a visão total dos benefícios do princípio democrático para a cidadania. A eleição é a forma racional de o conflito prevalecer na sociedade, portanto, não deve ser preterida na análise em razão de uma preferência do pesquisador por indicadores socioculturais. A verificação da permanência do princípio democrático requer uma análise global que leve em conta aspectos do procedimento eleitoral, da prestação de contas dos governantes - accountability - em conjunto com os indicadores socioeconômicos permitindo aos pesquisadores da área de qualidade da democracia analisar, de forma comparativa, a ausência ou não do princípio democrático nas sociedades latino-americanas (AMORIM; DIAS, 2012).

Com a finalidade de avaliar o impacto da confiança dos cidadãos latino-americanos na mídia e nas instituições políticas, o presente trabalho propõe uma abordagem quantitativa em que são correlacionadas algumas de suas percepções de confiança. Isso significa comparar os países da América Latina em seus diferentes efeitos de predisposições a fim de verificar o quanto tais predisposições de confiança estão correlacionadas. As setas presentes no quadro 1, evidenciam que tal impacto pode se dar de forma bidirecional, em que por estarem sendo feitas correlações entre duas atitudes, estas são mutuamente influenciadas. Assim, não existe uma direção causal nas análises, mas sim um impacto de formação continuada. 
Quadro 1 - Correlações associadas a Confiança nos Meios de Comunicação

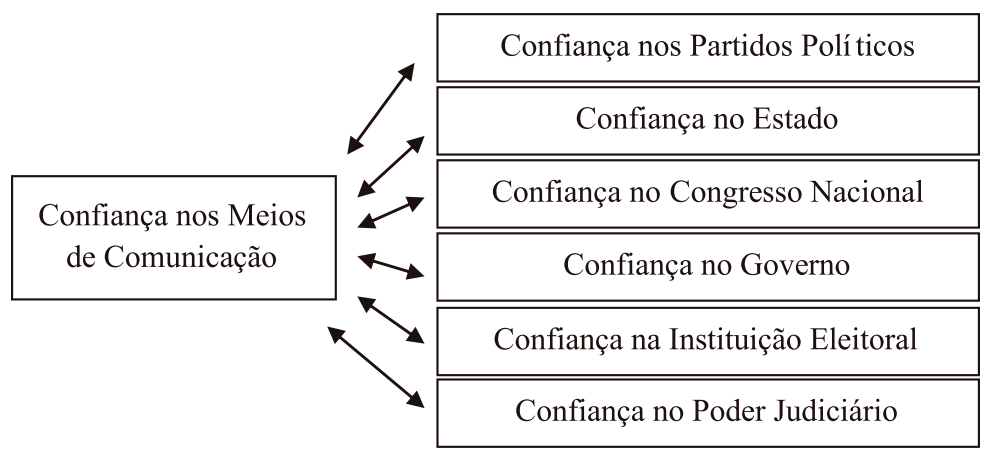

Fonte: Elaboração própria.

O comportamento político dos cidadãos será o resultado da força de tais associações, ou seja, na medida em que se verifica a existência de uma forte associação entre duas ou mais confianças, os cidadãos tendem a agir embasados na composição de suas predisposições. Nesse sentido, a hipótese de pesquisa é de que a confiança dos cidadãos na mídia está relacionada de forma inversamente proporcional à confiança destes em relação às instituições políticas, pois considera-se que o efeito resultante das associações é de desconfiança.

Os dados referentes as predisposições dos cidadãos latino-americanos são provenientes da coleta feita pela organização Latinobarômetro, no ano de 2015, em que são consideradas a percepção e a confiança dos residentes na América Latina com relação à política e à democracia. O Latinobarômetro é uma organização não-governamental de direito privado, com sede em Santiago do Chile, que apresenta dados referentes a opinião pública da população da América Latina. É uma fonte riquíssima de informações sobre a qualidade da democracia na região possibilitando aos pesquisadores uma abordagem mais substantiva do fenômeno.

A análise aqui proposta desenvolveu-se em três etapas. A primeira etapa possibilitou que se criasse um índice de confiança dos cidadãos com relação a mídia, denominado Índice de Confiança nos Meios de Comunicação, que varia entre 0 e 1 em que quanto mais próximo de 0 maior a ausência de confiança e, ao contrário, quanto mais próximo de 1 maior a confiança. Em uma segunda etapa, utilizou-se da técnica de análise fatorial, que permite avaliar as proximidades entre variáveis, pois buscava-se identificar as variáveis correlacionadas com a confiança na mídia. Na terceira etapa, após verificar a comunidade dos fatores, por meio da técnica de rotação dos componentes principais, foram incluídos no índice as variáveis de confiança: jornais, televisão e rádio. Esta técnica é preferível, uma vez que é possível transformar os dados sem descartar informação alguma, na medida em que se encontram as combinações lineares das variáveis (FIELD, 2009).

\footnotetext{
7 “Depois de extrair os fatores, é possível calcular em que grau as variáveis se adaptam a esses fatores (isto é, calcular a carga da variável em cada fator). Em geral, você descobrirá que a maioria das variáveis tem cargas altas no fator mais importante e cargas baixas nos demais fatores. Essa característica torna a interpretação difícil, assim, uma técnica chamada de rotação de fatores é usada para fazer a distinção entre fatores. Se um fator for um eixo classificatório ao longo do qual as variáveis podem ser traçadas, a rotação dos fatores gira esses eixos de modo que as variáveis estejam carregadas ao máximo somente em um fator” (FIELD, p. 566, 2009). Para mais informações sobre a técnica de Análise Fatorial e Rotação dos componentes principais consultar Field (2009).
} 


\section{ANÁLISE DOS DADOS}

No Gráfico 1, a seguir, apresenta-se o índice de forma agregada, pois desta forma é possível analisar comparativamente os países da América Latina.

Gráfico 1 - Índice Agregado de Confiança nos Meios de comunicação por países da América Latina

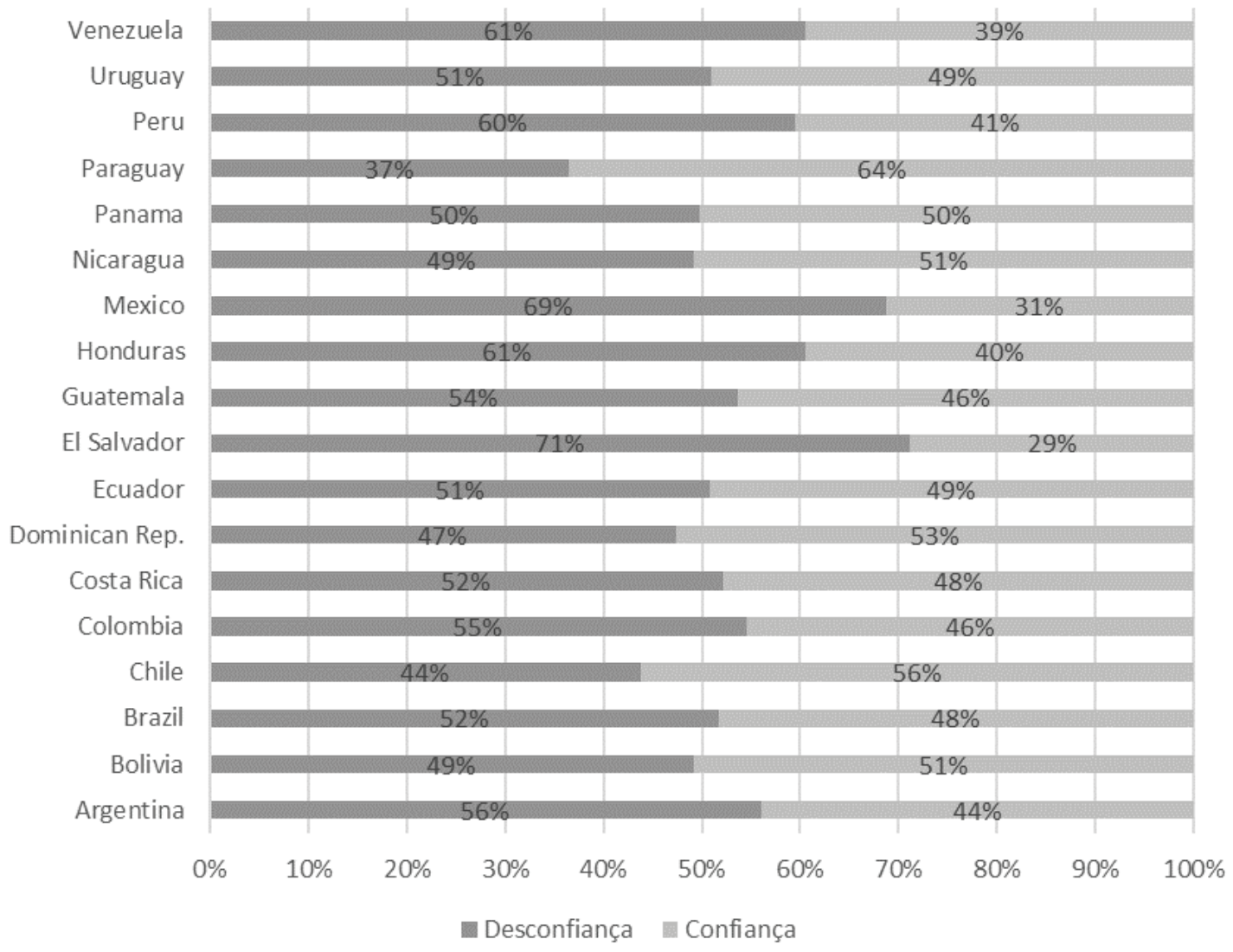

Fonte: elaboração própria com base nos dados do Latinobarômetro (2015).

A média no Índice de Confiança nos Meios de Comunicação considerando todos os países é de 0,46. O índice agregado, apresentado no Gráfico 1, considera duas categorias, porcentagem de pessoas que possuem desconfiança nos meios de comunicação (índice entre 0 e 0,50 ) e que possuem confiança nos meios de comunicação (índice entre 0,51 e 1). Optou-se por esta categorização, pois é possível realizar uma análise comparativa dos resultados dos países, a partir da Análise da Variação da Média Total. Os países que se destacam nessa análise, são os que apresentaram um alto percentual de desconfiança nos meios de comunicação, El Salvador (71\%), México (69\%), Venezuela e Honduras (61\%) e Peru (60\%). Já os países que apresentam o menor percentual de desconfiança foram Paraguai (37\%), Chile (44\%), República Dominicana (47\%) Nicarágua e Bolívia (49\%). Entre os países com menor desconfiança sobre os meios de comunicação é possível ressaltar a instabilidade política enfrentada pelo Paraguai e pela Nicarágua com deposições de presidentes ${ }^{8}$.

\footnotetext{
${ }^{8}$ Em 2009, Manuel Zelaya foi deposto da Presidência da Nicarágua pelo Congresso. Da mesma forma, em 2012, o então presidente Fernando Lugo foi deposto no Paraguai.
} 
A mídia como instituição semi-independente, perpassando instituições políticas e sociais, está num patamar de desconfiança pelos dados do Latinobarômetro, da mesma forma que tinha sido já constatada por O’Donnell (2011). Para este teórico das transições democráticas, o papel da mídia como mais um espaço de garantias de liberdades individuais é pouco percebido pela população, em virtude do avanço lento e gradual da cidadania nestas democracias. Ainda que em termos percentuais exista pouca diferença entre os países analisados, uma maior desconfiança dos cidadãos junto aos países que tiveram um passado violento de repressão da liberdade de expressão sinaliza pouca reflexão crítica das gerações mais recentes sobre o papel da mídia dentro do espaço democrático.

A desconfiança sobre os meios de comunicação afeta o papel da mídia para ser uma fonte de informação de qualidade para a população, além do papel de fiscalização dos agentes políticos. Este resultado recente do Latinobarômetro já refuta nossa hipótese de pesquisa e indica que muito da instabilidade vivida pelas democracias sul-americanas envolve a crítica ao enviesamento de setores da mídia sobre os acontecimentos políticos noticiados, que beneficiaria a elite econômica, militar e política destes países. O’Donnell (2011) aponta que a população desconfia da mídia e das instituições pela crença de que favorecem os interesses dos mais poderosos. E essa simbiose entre mídia e poder é mesmo presente se considerarmos que as elites são as que mais patrocinam o funcionamento das empresas de comunicação com anúncios e publicidade (MARQUES, 2018). Mudar a percepção da população será uma tarefa que levará algumas décadas, possivelmente.

A segunda etapa metodológica foi a elaboração de um modelo em que se verifica a influência das variáveis de confiança nos Partidos Políticos, no Estado, no Congresso Nacional, no Governo, no órgão eleitoral e no Poder Judiciário dos países da América Latina. Esta etapa surge no contexto de que é preciso aprofundar os resultados coletados. Para atingir o objetivo dessa etapa, verificou-se a correlação entre o índice de confiança nos meios de comunicação e a confiança dos cidadãos latino-americano nas instituições democráticas, usando-se a técnica da regressão linear. Assim, a fórmula utilizada foi:

$$
Y i c m c=\alpha+X p p+X g+X c n+X e+X i e+X p j+e
$$

Em que:

Yicmc $=$ Índice de Confiança nos Meios de Comunicação

$\alpha=$ Constante

Xpp $=$ Confiança nos Partidos Políticos

$\mathrm{Xg}=$ Confiança no Governo

$\mathrm{Xcn}=$ Confiança no Congresso Nacional

$\mathrm{Xe}=$ Confiança no Estado

$\mathrm{Xie}=$ Confiança nas Instituições eleitorais

$\mathrm{Xpj}=$ Confiança no Poder Judiciário

$\mathrm{e}=$ Erro 
Com relação ao poder explicativo, o $\mathrm{R}$ Square $\left(\mathrm{R}^{2}\right)$, o modelo tem capacidade explicativa de 23,4\% sobre relação entre a confiança nos meios e comunicação e as variáveis selecionadas para medir as atitudes políticas de confiança das instituições democráticas. Nesse sentido, para calcular de forma preditiva a atitude política dos cidadãos em todos os países geral, a fórmula encontrada foi a seguinte:

$$
\text { Yicmc }=, 282+X(, 049)+X(, 021)+X(, 120)+X(, 040)+X(, 093)+X(, 197)+e
$$

Tabela 1 - Análise da influência da confiança nos meios de comunicação sobre instituições democráticas por países.

\begin{tabular}{|c|c|c|c|c|c|c|c|c|c|}
\hline País & $\mathbf{R}^{2}$ & $\alpha$ & Xpp & $\mathrm{Xg}$ & Xen & $\mathbf{X e}$ & Xie & Xpj & $\mathrm{e}$ \\
\hline Argentina &, 118 &, 357 &, 017 &,- 205 & ,267 &,- 053 &, 055 & ,194 &, 230 \\
\hline Bolívia & ,236 & ,304 &, 015 &, 127 &, 112 &, 025 &, 055 & ,160 & ,194 \\
\hline Brasil & ,262 &, 269 &, 005 &, 081 &, 119 & ,082 &, 152 &, 160 & ,205 \\
\hline Chile & ,286 & ,299 &,- 104 &, 189 &, 160 &, 028 & 154 & 084 & ,188 \\
\hline Colômbia &, 273 &, 265 &, 161 &, 048 &, 162 & ,026 &, 117 &, 104 & ,206 \\
\hline Costa Rica & ,288 & ,276 & ,028 & ,101 &, 042 &, 004 & ,180 & ,138 & ,213 \\
\hline República Dominicana & ,398 & ,201 &,- 012 &, 131 &, 142 & ,088 &, 136 & ,195 & ,241 \\
\hline Equador & ,325 &, 256 & ,144 &,- 057 &, 062 &, 034 &, 038 & ,364 & ,213 \\
\hline El Salvador & ,282 & ,204 &, 140 &,- 122 & ,189 &, 052 &, 068 & ,299 & ,231 \\
\hline Guatemala & ,356 & ,264 &, 067 & ,004 & ,218 &, 062 & ,104 &, 170 & ,209 \\
\hline Honduras & ,279 &, 252 & ,106 &,- 012 &, 128 &, 114 & ,139 & ,193 & ,246 \\
\hline México & ,351 & , 169 & ,106 &, 050 & ,215 & ,032 &, 147 &, 127 & ,202 \\
\hline Nicarágua & ,293 & ,294 &, 013 & ,042 &, 159 & ,122 & ,020 & ,167 & ,225 \\
\hline Panamá & ,335 & ,243 & ,086 & ,105 & ,091 & ,086 &, 101 & ,166 & ,204 \\
\hline Paraguai & ,175 & ,374 & ,009 & ,049 & ,093 &, 052 &, 073 & ,216 & ,227 \\
\hline Peru & ,277 & ,239 & ,038 & ,049 &, 117 &,- 004 &, 167 & ,247 & , 195 \\
\hline Uruguai &, 138 & ,294 &,- 033 &,- 084 &, 080 & ,095 &, 042 & ,246 & ,229 \\
\hline Venezuela & ,109 &, 344 &, 111 &,- 129 &, 075 &,- 046 &, 015 & ,266 & ,237 \\
\hline
\end{tabular}

Fonte: Latinobarômetro, 2015.

Considerando, por fim a terceira etapa das análises, o índice de confiança nos meios de comunicação foi rodado para cada país. Os resultados podem ser examinados na tabela 1. A República Dominicana constitui-se no único país que o modelo apresenta uma relação considerada robusta ( $\mathrm{R}^{2}$ acima de 40 ), ou seja, é o único país aonde a confiança nos meios de comunicação é atrelada as instituições políticas. Mesmo se tratando de um caso isolado, a existência dessa correlação entre a confiança nos meios de comunicação e algumas outras instituições específicas pode indicar processos no qual foi constituída tais atitudes de apreço a informação veiculada na mídia. Diferentemente dos demais países da América Latina, a República Dominicana saiu da ditadura militar, comandada pelo general Rafael Trujillo (1930-1961), para a democracia no começo da década de 1970.

Segundo Gúzman y Ramírez (2010), o sistema partidário dominicano apresentou um satisfatório grau de nacionalização partidária nas eleições presidenciais e municipais no intervalo de 1994 a 2008. Isso se deve à estratégia das principais siglas - Partido Revolucionário Dominicano [PRD], 
Partido de la Liberación Dominicana [PLD] e Partido Reformista Social Cristiano [PRSC] - fazerem coligações eleitorais com os partidos regionais em todos as localidades. Dessa forma, os principais partidos reforçaram sua predominância no nível local ao mesmo padrão de domínio nas eleições presidenciais. É um indicativo de que o processo de realizar as mudanças na percepção de confiança na mídia e nas instituições políticas teria que acontecer antes do período neoliberal, de finais da década de 1980, nos outros países da região.

De outro lado, percebe-se uma relação constante de confiança no poder judiciário no modelo explicativo. Principalmente porque a maioria dos países analisados apresentaram como fator mais forte a confiança neste poder, e, na maioria dos casos, uma correlação positiva. Os países que fugiram deste padrão foram México, Guatemala, Colômbia e Argentina, que apresentaram como fator mais forte de confiança o Congresso Nacional. No caso argentino, a forte politização da sociedade pode explicar a característica de confiança de que a classe política resolva os problemas sociais. Os demais países enfrentam a décadas problemas com o crime organizado e organizações paramilitares como, por exemplo, as FARC na Colômbia. Tal situação exacerbada de violência pode recair na conta da impunidade, no qual o setor judiciário é responsável por administrar punições, sendo vista negativamente pelos cidadãos.

Já no Chile, a confiança nos meios de comunicação está atrelada a confiança no governo. É possível destacar este caso como paradigmático, para os países que tiveram um passado ditatorial duradouro, no desenvolvimento das atitudes de confiança democrática correlacionado a confiança nos meios de comunicação. James Cockcroft (2013), por exemplo, aponta que a interferência do governo norte-americano foi decisiva para a derrubada do presidente Salvador Allende em 1973 . Essa interferência externa se deu tanto pelo patrocínio da dissidência de militares das Forças Armadas chilenas, quanto de organizações da sociedade civil conservadoras e ainda pelo fomento de meios de comunicação opositores ao governo socialista de Allende. Percebe-se, então, que veículos de comunicação estão em conflito com o poder por interesses "ocultos" do mercado e de outras nações. Talvez o discurso de neutralidade da imprensa latino-americana não seja percebido assim pela população, acarretando similaridades no grau de desconfiança destinada as instituições políticas. Portanto, a avaliação do modelo permite verificar a existência de correlação entre a formação de atitudes democráticas de desconfiança com relação a instituições, em conjunto com valores de desconfiança nos meios de comunicação, embora de maneira diferenciada em cada país.

\section{CONCLUSÕES}

Devido ao papel de informação da mídia, que impacta na avaliação negativa ou positiva que os cidadãos possuem sobre o sistema político, seria esperado que a população tivesse mais confiança nela do que nas instituições políticas, pois estas últimas estariam mais envolvidas em escândalos de

${ }^{9}$ A ditadura no Chile, comandada pelo general Augusto Pinochet, durou de 1973 até 1990. 
corrupção. Considerando-se os dados apresentados, nossa hipótese de pesquisa de que a confiança dos cidadãos na mídia está relacionada de forma inversamente proporcional à confiança destes em relação às instituições políticas mostrou-se invalidada, sinalizando uma grande interrogação para o futuro democrático dos países da América Latina.

Se a mídia não é vista como mediador entre as instituições políticas isso abre espaço, de um lado, para que estas instituições políticas deslegitimem a liberdade de expressão e o papel da imprensa de formadora de opinião, favorecendo um clima de acirramento entre a classe política e os meios de comunicação, e, de outro lado, dificulta a crença em valores democráticos, pois todos as instituições são vistas com desconfiança. Portanto, este estudo de qualidade da democracia mostra que em vários países sul-americanos a consolidação da democracia é uma dúvida persistente. A cultura política autoritária ainda paira nas sociedades latino-americanas, mostrando que o embate de narrativas sobre o passado ditatorial continua vivo.

Além disso, foi percebida uma correlação fraca entre confiança na mídia e nas instituições políticas, ou seja, há poucos indícios para creditar que uma confiança nos meios de comunicação está atrelada também as demais instituições, excetuando o caso da República Dominicana que teve uma correlação robusta. Nos demais países, apenas algumas instituições tinham correlações de nível alto, ou seja, a confiança das pessoas naquilo que a mídia informa está atrelado no quanto elas confiam em instituições políticas, tais quais o Congresso, Partidos, Judiciário, etc. Dessa forma, se a mídia, eventualmente, vier a questionar a legitimidade de algumas instituições, a população irá acreditar

que estas instituições, questionadas pelos meios de comunicação, estão com problemas. É importante ressaltar, no entanto, a necessidade de se discutir mais, em futuras pesquisas, a percepção da qualidade da democracia em contextos sociais afligidos sucessivamente por escândalos de corrupção e de instabilidade institucional.

\section{REFERÊNCIAS}

ALMOND, G.; VERBA, S. The Civic Culture: Political attitudes and democracy in five nations. Boston: Little, Brown, 1965.

AMORIM, Maria Salete; DIAS, Rodrigo. Dimensões teóricas e práticas da qualidade da democracia. Revista Debates, Porto Alegre, v. 6, n. 3, p. 79-96, 2012.

ÁVILA, Carlos Federico. Los límites de la participación política en Brasil: la calidad de la democracia en perspectiva. IN: LUCCA, Juan Bautista et al. (Org.). Desafíos democráticos latinoamericanos en perspectiva comparada. Rosário: Editora Universidad Nacional de Rosario, 2017. 
BAQUERO, Marcelo. Avaliando o potencial de fatores culturais na construção da democracia na América Latina: uma comparação entre 2005 e 2010. Revista Debates, v. 6, p. 9-34, 2012.

COCKCROFT, James. Cronología: Chile 1970-1973. IN: AGUILERA, Pilar; FREDES, Ricardo (Orgs). Chile: el otro 11 de septiembre. Santiago: Editora Ocean Sur, 2013.

DAHL, Robert. Polyarchy: participation and opposition. New Haven, Yale University Press, 1971.

DIAMOND, Larry; MORLINO, Leonardo. Quality of democracy. An overview. Journal of Democracy, v. 15, n. 4, p. 23-31, 2004.

FIELD, Andy. Descobrindo a estatística usando o SPSS. Porto Alegre: Artmed, 2009

GIANNONE, Diego. Political and ideological aspects in the measurement of democracy: The Freedom House case. Democratization, v. 17, n. 1, p. 68-97, 2010.

GUGLIANO, Alfredo. Apontamentos sobre o conceito de qualidade da Democracia. Revista Debates, Porto Alegre, v.7, n.1, p.229-243, jan.-abr. 2013.

GÚZMAN, Carlos Enrique; RAMÍREZ, Adriana. Explorando los sistemas de partidos de República Dominicana: un análisis de la nacionalización, 1994-2008. V Congreso Latinoamericano de Ciencia Política. Asociación Latinoamericana de Ciencia Política, Buenos Aires, p. 01-36, 2010.

HJARVARD, Stig Midiatização: teorizando a mídia como agente de mudança social e cultural. Matrizes, vol. 5, núm. 2, 2012, p. 53-91.

HJARVARD, Stig. News Media and the Globalization of the Public Sphere. In: HJARVARD, Stig. (ed.). News in a Globalized Society. Göteborg: Nordicom. 2001.

HUNTINGTON, Samuel. A Terceira Onda: democratização no final do século XX. São Paulo: Ed. Ática, 1994.

HUR, Domenico; LACERDA JÚNIOR, Fernando. Ditadura e insurgência na América Latina. Psicologia: Ciência e Profissão, v. 37 (núm. esp.), pp. 28-43, 2017. 
INGLEHART, R.; WELZEL, C. Uma teoria revisitada da modernização. Modernização, mudança cultural e democracia. São Paulo: Verbena, 2009.

IAZZETTA, Osvaldo. Democracia, Calidad de la democracia y Democratización. Revista Debates, Porto Alegre, v. 7, n. 1, pp. 139-150, 2013.

KRAUS, Stephen J. Attitudes and the prediction of behavior: A meta-analysis of the empirical literature. Personality and social psychology bulletin, v. 21, n. 1, p. 58-75, 1995.

LAUTH, Hans-Joachim. Critérios básicos para a democracia: é a responsividade parte de seu círculo íntimo? Revista Debates, Porto Alegre, v. 7, n. 1, p. 115-138, 2013.

LUNT, P.; LIVINGSTONE, S. Is “mediatization” the new paradigm for our field? A commentary on Deacon and Stanyer $(2014,2015)$ and Hepp, Harvard and Lundby. Media, Culture and Society, v. 38, Issue 3, p. 462-470, 2016.

LIMA, Venício A de. Mídia: crise política e poder no Brasil. São Paulo: Editora Fundação Perseu Abramo, 2007.

LIMA, Venício A de. Política de comunicações: um balanço dos governos Lula [2003-2010]. São Paulo: Publisher Brasil, 2012.

MARQUES, Rodolfo. A Mídia e a Lei: Análise comparada das políticas de regulação dos meios de comunicação no Brasil e na Argentina no início do século XXI. Aurora: revista de arte, mídia e política. Tese de Doutorado em Ciência Política. Porto Alegre, UFRGS, 2018.

MOISÉS, José Álvaro e MENEGUELLO, Rachel. A Desconfiança política e os seus impactos na qualidade da democracia. São Paulo: Editora Unesp, 2013.

MOISÉS, José A (org.). Democracia e confiança. São Paulo: Edusp, 2010.

MORLINO, Leonardo. Legitimacy and the quality of democracy. International Social Science Journal, v. 60, n. 196, p. 211-222, 2010. . Explicar la calidad democrática: ¿Qué tan relevantes son las tradiciones autoritarias? Revista de Ciência Política, v. 27, n. 2, pp. 03-22, 2007. 
MUNCK, Gerardo; MANTILLA, Sebastián (eds.). La calidad de la democracia: perspectivas desde América Latina. Quito: CELAEP y Fundación Hanns Seidel, 2013. 299 p.

O’DONNELL, Guillermo. Democracia, agência e estado: teoria com intenção comparativa. São Paulo: Paz e Terra, 2011.

PRZEWORSKI, A. What makes democracies endure? Journal of democracy, v. 7, n. 1, p. 39-55, 1996.

SCHMITTER, Philippe. The Quality of Democracy: The Ambiguous Virtues of Accountability. Journal of Democracy, v. 15, n. 49, 47-60, 2004.

STROMBACK, J; VAN AELST, P. Why Political parties adapt to the media: exploring the fourth dimension of mediatization. The International Communication Gazette, v. 75, n. 4, p. 341-358, 2013.

TILLY, Charles. Democracy. Cambridge: Cambridge University Press, 2007. 